\title{
KINEMATICS AND FORCES IN THE ABOVE-KNEE PROSTHESIS DURING THE STAIR CLIMBING
}

\author{
Vucina, A. ; Hudec, M. ${ }^{* *} \&$ Raspudic, V. \\ *Faculty of Mechanical Engineering and Computing, University of Mostar \\ Matice hrvatske bb, 88000 Mostar, Bosnia and Herzegovina \\ E-mail: adisa.vucina@tel.net.ba; vesna.raspudic@tel.net.ba \\ ** Faculty of Mechanical Engineering, University "Djemal Bijedic", Mostar \\ USRC Sjeverni logor, 88000 Mostar, Bosnia and Herzegovina
}

\begin{abstract}
The most modern generation of controlled AK prostheses is considered as important step forward in technology of manufacture of AK prostheses, since they offer the highest proximity to human walk. However, so far the problem of climbing the stairs by transfemoral amputee has not been resolved. The reason for unresolved problem of upstairs movement of persons with AK prosthesis lies in a need to introduce an external source of energy, which would provide the user with energy required for lifting a body when climbing the stairs.

The kinematic analysis of movement of the AK prosthesis with a build-in hydraulic cylinder connected to an external source of power is intended to prove that there is a real possibility for a person with an AK prosthesis to climb stairs. An analysis was carried out of the prosthesis movement in a sagital plane for the period of climbing from the first contact of the artificial foot with the step of a stair until the moment of its separation. Trajectories of characteristic points on the prosthesis were recorded for the examinee climbing three staircases with different gradients: shallow SH $\left(25^{\circ}\right)$, moderate $\mathrm{M}\left(30^{\circ}\right)$ and steep ST $\left(36^{\circ}\right)$. The reaction force on stair during the movement of an AK prosthesis is analyzed. For more detailed analysis of climbing of a transfemoral amputee, an analysis of reaction force of stair for healthy persons has been carried out. The ELITE system with two CCD cameras and a Kistler platform for measuring the force on the surface were used during measurements.
\end{abstract}

Key Words: Above-Knee Prosthesis, Hydraulic Cylinder, Stair Climbing

\section{INTRODUCTION}

Loss of limb has been a problem as long as man has been in existence [1]. The earliest known record of a prosthesis being used by man was made by the famous Greek historian, Herodotus (484 b.c.). Human movement is very complex activity and product of the complex internal and external forces acting on human body. Besides these mechanical acts, there are also stresses and friction in the joints, dynamics of muscles as active factor of movement and bones as levers. Extremely complex biomechanical process includes movement in three dimensions of the system which requires coordinated control of the central neural system which surpasses sophisticated prostheses made by man. The complexity of the normal walk from where of is developed a prosthetic walk leads to improvement of intelligent control versus the classic methods. For the transfemoral amputee the loss of the knee is undoubtedly significant problem considering the control and security, and also energy consumption [2]. Each amputee tries to adjust his own way of walking as much as he can inside the limitations of chosen prosthesis. However, the functional requirements and forces generated during the 
movement are closely studied in order to adjust the prosthesis as much as possible to specific needs of every particular person [3, 4]. The modern above-knee prostheses make walking to amputees much easier. Profound study is given to knee joint and ankle joint of the prosthesis [5-12].

There are computer controlled prostheses today which adjust the movement of the prosthesis to any speed and remarkably decrease step deviations and amputee effort during the walk. The most modern generation of controlled AK prostheses with computer-controlled phases of standing and swinging are considered to be an important step forward in the technology of the manufacture of AK prostheses, since they offer the closest proximity to natural walking [13]. The users of these prostheses are able to walk freely and safely at different speeds, even when walking on rugged ground or down stairs [14]. To date, however, the problem of climbing stairs for a transfemoral amputee has not been resolved. The users of the modern prostheses, such as the so-called "intelligent" prostheses or computer-controlled prostheses, still can not climb stairs as nonamputees do. The underlaying reason for this unresolved problem of stair climbing for a person with an AK prosthesis lies in the need to introduce an external source of energy, which would provide the user with the energy required to lift the body when climbing stairs. This approach is ussually disregarded due to the presumption of a need for a robust external source of power, which would be unacceptable to the user.

This paper is intended to prove a real possibility that a person with an AK prosthesis can climb stairs through a kinematic analysis of the movement of an AK prosthesis with a built-in hydraulic cylinder connected to an external source of power. Also, it is intended to prove that it is feasible to create a drive for an AK prosthesis for stair-climbing with a unit whose weight and over-all dimensions would not interfere with the comfort of the prosthesis user.

\section{MEASUREMENT OF KINEMATIC VALUES}

\subsection{Modification of AK prosthesis}

The recording and measuring of one transfemoral amputee are carried out (age 70, weight 70 $\mathrm{kg}$, height $172 \mathrm{~cm}$, amputation on right side). The AK prosthesis ENDOLITE type SFEUK (Stanceflex Uniaxial Knee Chassis) with an Endolite Multiflex foot is fitted to the transfemoral examinee (Fig. 1). Using this type of prosthesis it was easy to build in a new hydraulic cylinder by substituting its damper in the knee joint without causing any destruction of the prosthesis structure. The existing damper in the knee joint is substituted with a specially constructed hydraulic cylinder. The prosthesis is made of new materials (composites), so it has a low mass. This is very important due to the possibility of future changes in mass, as it permits a change of mass within an allowed range. The constructive conception of the hydraulic cylinder was defined, but the mechanical and hydraulic characteristics (force, pressure, flow rate) had been defined previously with consideration to the available space and connection points in the existing prosthesis $[15,16]$. 


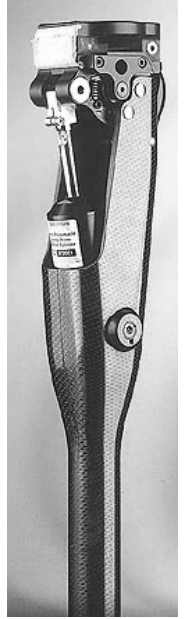

a)

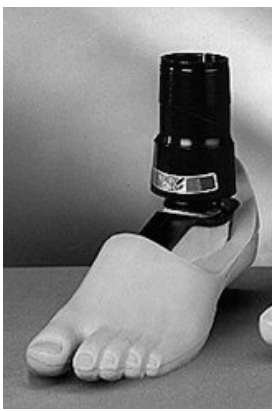

b)

Figure 1: Above-knee prosthesis ENDOLITE type SFEUK (a), MULTIFLEX foot (b).

\subsection{Organization of measurement}

Five passive markers with $1 \mathrm{~cm}$ diameters were used for marking characteristic points on the AK prosthesis. They were placed laterally on the right side of the prosthesis at the following points: hip, knee joint line, ankle joint line, heel and fifth toe of the prosthetic foot to study the motion of the hip, knee and foot of the prosthesis (Fig. 2). Three staircases with different

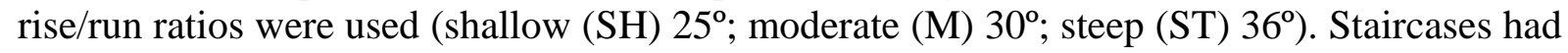
banisters on the left side. The staircase and examinee were always in a calibrated space of length 2,2 m, height $1,8 \mathrm{~m}$ and width $1,5 \mathrm{~m}$ (Fig. 3). Two CCD cameras of ELITE system were used [17]. Since the examinee did not feel ready to climb stairs without a help of the banister in this phase of prosthesis development, this method of climbing stairs was excluded from the study. In order to ensure a slow and safe climb by the examinee, the flow rate in the hydraulic installation was adjusted to a low value, $0,18 \mathrm{l} / \mathrm{min}$ (the pulling out speed of the piston was $1,475 \mathrm{~cm} / \mathrm{sec}$ ). The movement of the AK prosthesis in a sagital plane was analyzed, from the moment of the first contact of the prosthetic foot with a step, until the moment of separation from the same step. A series of six reviews on each staircase were carried out.

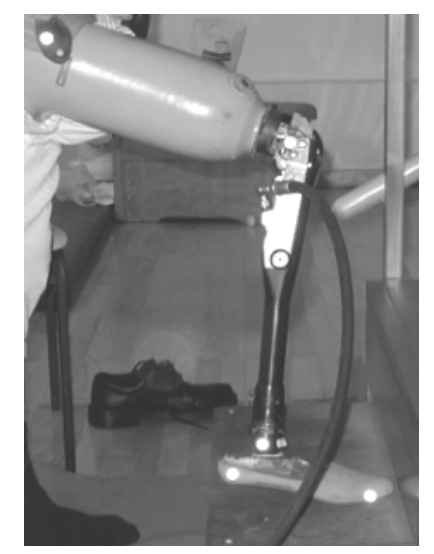

Figure 2: The AK prosthesis of amputated examinee in the moment of the contact with the stair. 


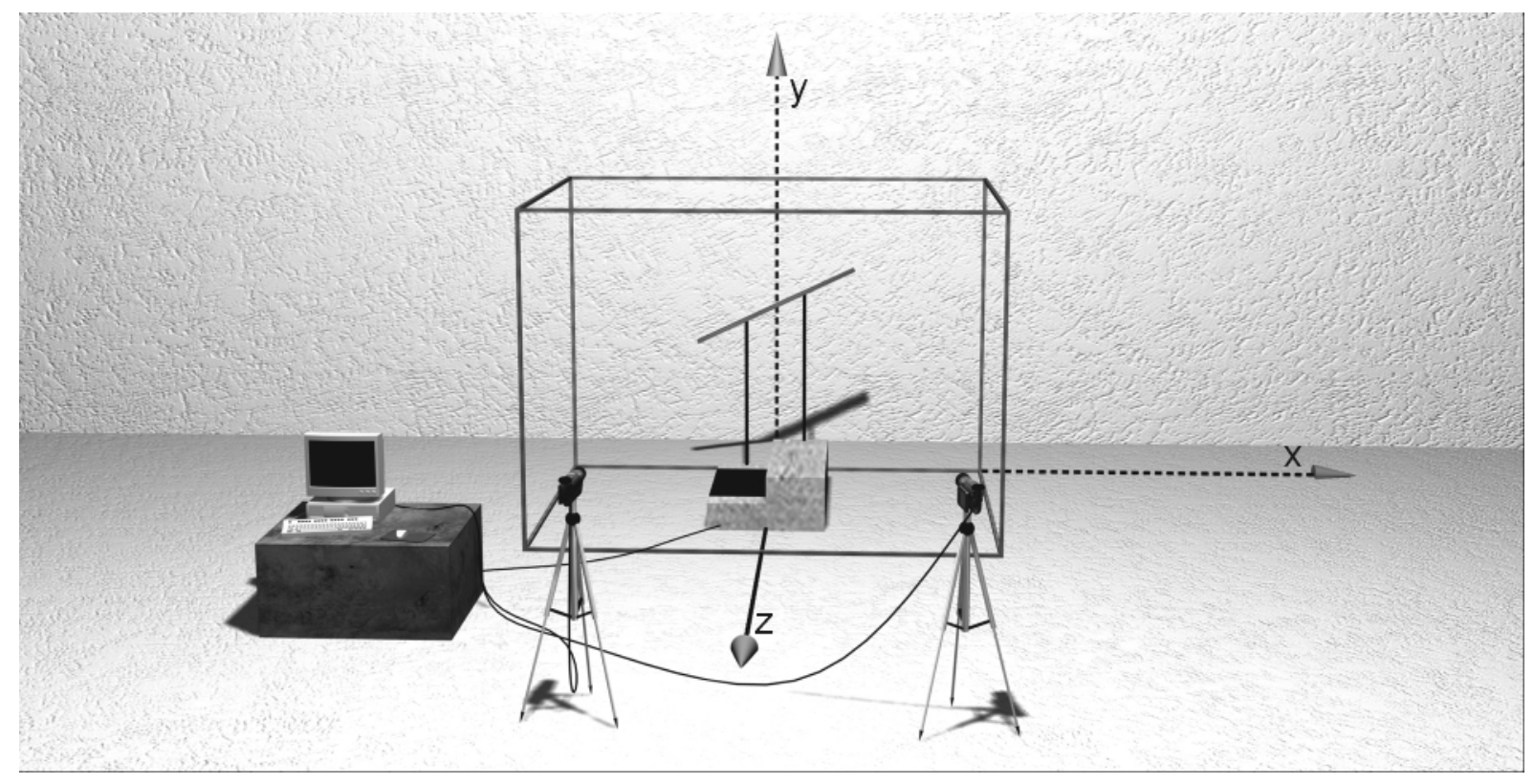

Figure 3: Calibrated space and reference coordinate system.

\subsection{Results}

After the collection and processing of data gathered by measuring and recording, an analysis of the characteristics of recorded periods at staircases with different ratios was carried out. The characteristic angles of the AK prosthesis in a sagital plane are chosen for analysis of the climb, these are the hip angle, knee angle and foot angle (the angle between foot and stair). Using the recorded coordinates of characteristic points on the prosthesis, specific angles of the prosthesis in a sagital plane are defined. In addition to this series of characteristics, the analysis included the highest pressure of the hydraulic installation of the prosthesis achieved during the climbing, and also the knee moment generated by this pressure in order to make possible this stair-climbing by the transfemoral amputee.

Table I shows the average values of the characteristic angles of the AK prosthesis for climbing on three staircases with different ratios: shallow (SH) $25^{\circ}$; moderate $(\mathrm{M}) 30^{\circ}$; steep (ST) $36^{\circ}$.

Figure 4 presents the period of the AK prosthesis movement during the climbing recorded by the ELITE system, and a diagram of characteristic angles of the prosthesis during the period of climbing divided into four phases.

Table I: Hip angle, foot angle and knee angle at first contact of the prosthetic foot with the step, minimal knee angle at the moment of maximal extruding of the AK prosthesis, with corresponding time defined as percent of the climbing period $\left(\mathrm{t}_{\mathrm{p}}\right)$.

\begin{tabular}{|l|c|c|c|c||c|c|}
\hline \multicolumn{1}{|c|}{ Staircase } & $\begin{array}{c}\mathrm{t}_{\mathrm{p}} \\
(\mathrm{sec})\end{array}$ & $\begin{array}{c}\text { Initial hip } \\
\text { angle }\left(^{\circ}\right)\end{array}$ & $\begin{array}{c}\text { Initial foot } \\
\text { angle }\left(^{\circ}\right)\end{array}$ & $\begin{array}{c}\text { Initial knee angle } \\
\left({ }^{\circ}\right)\end{array}$ & $\begin{array}{c}\text { Min. knee } \\
\text { angle }\left(^{\circ}\right)\end{array}$ & $\begin{array}{c}\text { Time } \\
\left(\% t_{p}\right)\end{array}$ \\
\hline Shalow SH $\left(25^{\circ}\right)$ & 3,52 & 57,932 & $-16,593$ & 73,917 & 0,961 & 42,614 \\
\hline Moderate M $\left(30^{\circ}\right)$ & 2,06 & 60,823 & $-10,167$ & 69,701 & 0,974 & 60,194 \\
\hline Steep ST $\left(36^{\circ}\right)$ & 1,68 & 45,085 & $-2,693$ & 44,954 & 0 & 54,762 \\
\hline
\end{tabular}



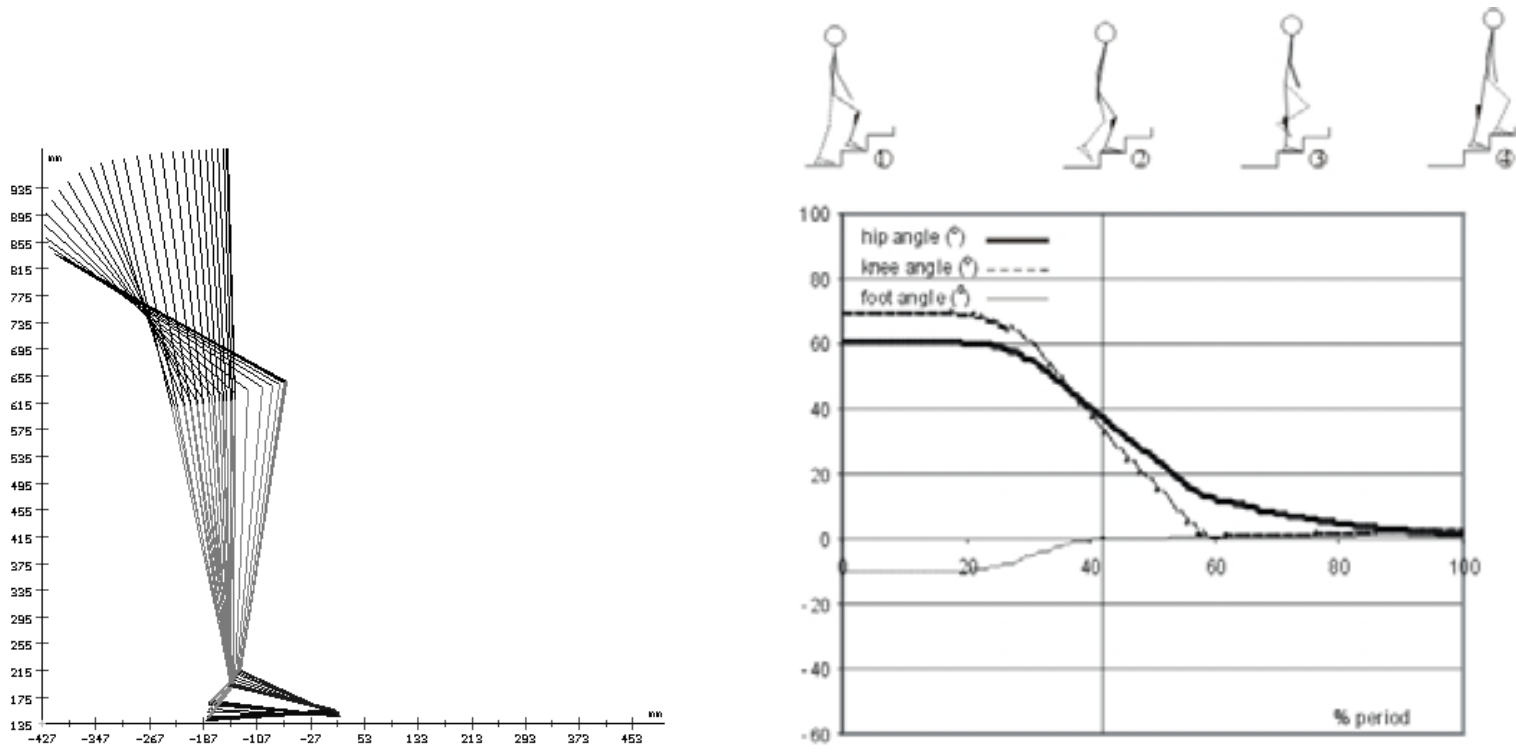

Figure 4: Climbing with AK prosthesis on a moderate staircase. Left: Movement of AK prosthesis during the period of climbing;

Right: Diagrams of characteristic angles during the climbing.

\subsection{Presure in the hydraulic instalation}

The average pressure in the hydraulic installation during climbing with the AK prosthesis was $86 \times 10^{5} \mathrm{~Pa}$. The maximal moment produced by the force of the hydraulic cylinder during climbing with the use of a banister was $54,28 \mathrm{Nm}$, and during the climbing with the use of both a banister on the left side and pulling on a horizontal rope with the right hand was 53,07 Nm.

Figure 5 presents change of the moment in the knee joint generated by the force of the hydraulic cylinder for climbing while holding the banister on the left side and climbing with holding the banister on the left side and pulling horizontal rope by right arm.
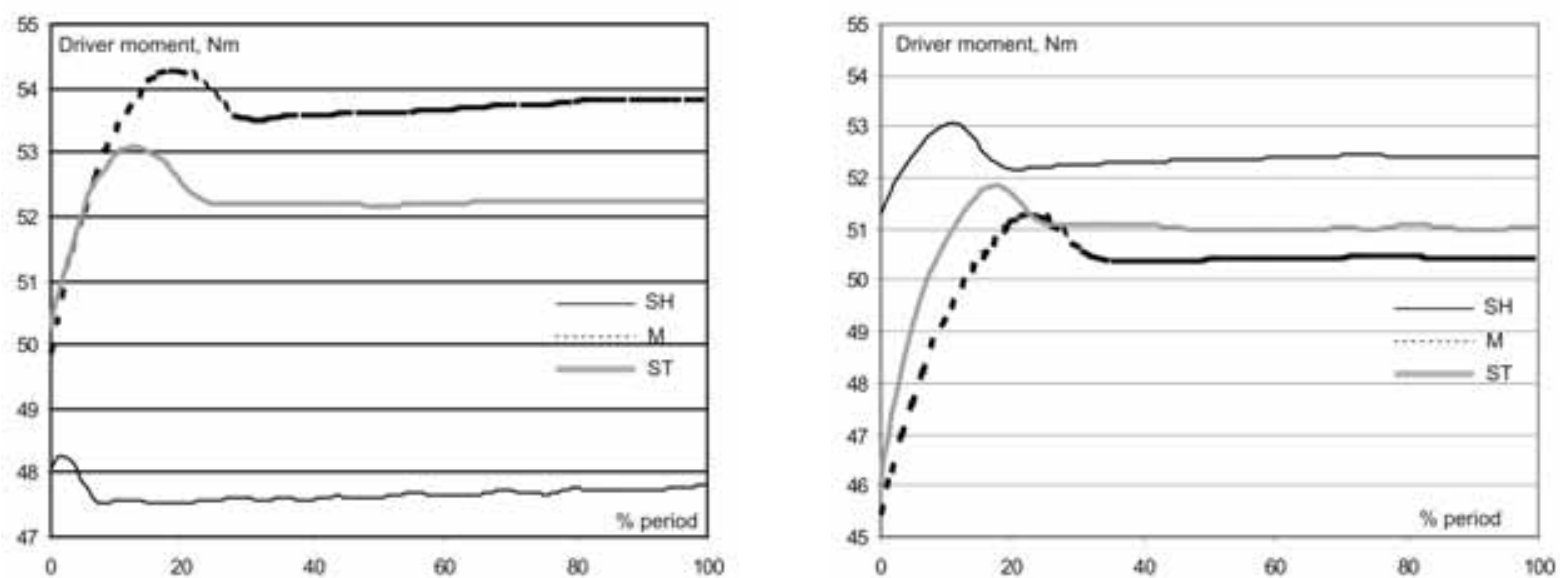

Figure 5: Moment in the knee joint generated by the force of the hydraulic cylinder.

Left: Climbing while holding the banister on the left side;

Right: Climbing with holding the banister on the left side and pulling horizontal rope by right arm. 


\subsection{Analysis of climbing of person with AK prosthesis}

In order to achieve stability and prepare for climbing, the amputee stands near the first step, and positions his AK prosthesis so the foot is touching the stair with the front part and is inclined to the surface of the stair. When the subject feels stable, the handle of the manifold is pulled from the neutral position and the piston of the hydraulic cylinder starts to pull out. Because of the increase of the pressure in the hydraulic installation and movement of the piston, the heel of the prosthetic foot strikes the stair and almost simultaniously the healthy leg is raised from the ground (Fig. 6).

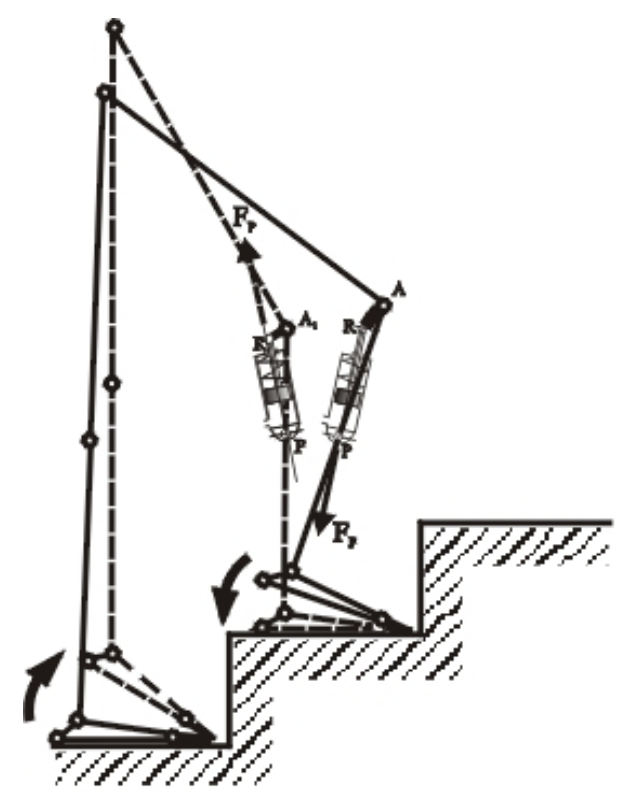

Figure 6: Mechanism of AK prosthesis in initial position (continuous line) and after the heel strike (dashed line).

Since the prosthetic foot is held completely onto the stair, the force of the cylinder extends the AK prosthesis in the knee joint and lifts the body of the transfemoral amputee. At the moment that the prosthetic heel lands on the step, the left leg separates from the ground and is swung up in order to get it onto the second step and lift the body. The period of climbing for the transfemoral amputee can be divided into four phases (Fig. 4). The first phase is the first contact of the prosthetic foot with the stair when the examinee touches the stair with the front of his prosthetic foot. This initial phase lasted on the shallow staircase 34,386 \% of the total period of climbing, on the moderate staircase 40,319 \% and on the steep staircase $11,820 \%$. The initial foot angle to the surface of the stair was: on the shallow staircase $16,808^{\circ}$, on the moderate $9,641^{\circ}$ and on the steep $5,422^{\circ}$. It was noted that as the ratio of the staircase increased the initial foot angle decreased and the lenght of the initial phase decreased. The second phase of climbing begins with the pulling of the manifold handle, in which the pulling out of the piston starts in the knee joint of the AK prosthesis. The first reaction is that the prosthetic heel strikes and the almost simultaneous separation of the left leg from the ground, as the knee angle and hip angle decrease. Then begins the third phase of climbing, when the prosthetic foot is resting on the step and the healthy leg swings up in order to touch the second step and lift the body of the amputee. At this phase extension of the AK prosthesis in the knee joint continues until the extension is complete. The fourth phase begins at the moment when the foot of the left, healthy leg is resting entirely on the second step and prosthetic foot separates from the first step. 


\section{VERTICAL REACTION FORCE OF THE STEP}

Vertical reaction force of the first step was measured during the climbing of one examinee with the AK prosthesis connected to an external source of power (age 70, weight $70 \mathrm{~kg}$, height $172 \mathrm{~cm}$, amputation on the right side), and four nonamputated examines (age 26,5 $\pm 8,6$; mass $70,9 \pm 6,6 \mathrm{~kg}$; height $176,25 \pm 7,75 \mathrm{~cm}$ ). Vertical reaction forces of the stair were measured for the examinees while climbing three staircases with different rise/run ratios: shallow (SH) $25^{\circ}$, moderate (M) $30^{\circ}$ and steep (ST) $36^{\circ}$.

The healthy examinees were tested in four ways of climbing: slow climbing, climbing with the use of left side banister hand-hold, climbing with pulling of a horizontal rope by right hand, and climbing at a speed the examinees deemed their normal speed.

Because of the safety of amputated examinee, he was tested in two ways of climbing: with the use of a left side banister hand-hold, and with simultaneous use of the banister and pulling a horizontal rope by right hand. Vertical reaction forces of the first step of a stair were measured for the period lasting from the moment of the first contact of the right foot (prosthetic foot) with a step until the moment of its separation. Series of six reviewing were carried out due to possibility of no full contact of the foot with a step (force platform).

\subsection{Analysis of vertical reaction force}

For the analysis of the reaction force of a stair, detailed analysis of its vertical component for all typical samples of climbing for each examinee was carried out. The first and second peak and valley of curve of vertical reaction force were defined. The goal of analysis was to establish influence of the run/rise ratio and ways of climbing on the reaction force of a stair. Forces were normalized through dividing with the weight of examinees, and the time is normalized in the way that it was expressed as a percent of contact duration. This study established that way of climbing influences on the vertical reaction force of the stair.

For the healthy examinees it was noticed that the characteristic peaks of the vertical reaction force during the climbing at normal speed were greather then during the slow climbing. During the climbing at normal speed, the averige period of climbing was shorter for $24,5 \%$ then averige period for slow climbing, for the climbing at normal speed the first peak was $4 \%$ greather and the second peak was $13 \%$ greather than for the slow climbing. The valley of curve for slow climbing was $12 \%$ greather than the valley for climbing at normal speed. During the climbing with pulling a horizontal rope by the right hand, it was not found out the influence of the pulling force on the first and second peak and valley of the vertical reaction force (the averige pulling force was $17,5 \%$ of examinees weight). The largest impact on the vertical reaction force was made by climbing with use of the banister hand-hold on the left side. Comparing with climbing without use of the banister, during the climbing with use of the banister hand-hold on the left side the first peak was $10 \%$ lower, the second peak was 13 \%lower, and valley was $6 \%$ lower. In the case of climbing with holding a banister on the left side, examinee was inclined to his left side so he released his right foot for a considerable amount of his weight (10-13\%) which would be lifted up on the second step. Figure 7 presents a curve of the vertical reaction force of the first step of a staircase during the slow climbing with and without the use of the banister on the left side of the examinee (the case of climbing on the steep staircase). 


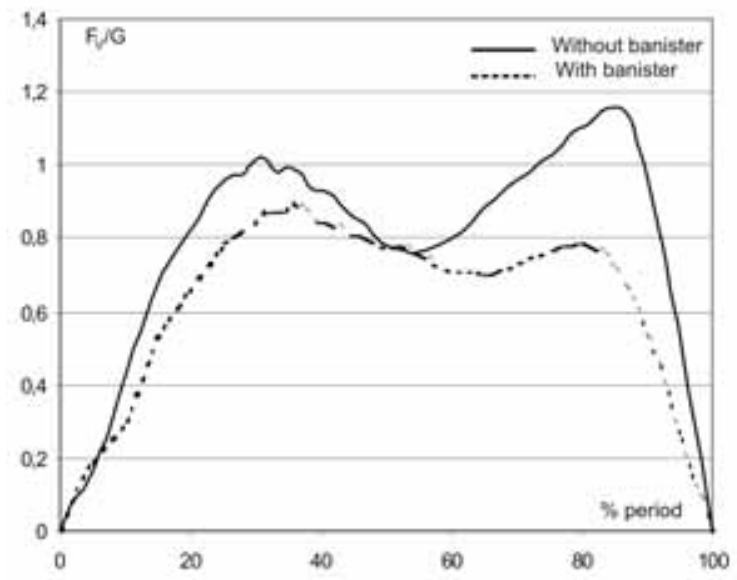

Figure 7: Diagram of the vertical reaction force of the first step of a stair (the case of a slow climbing with and without a use of a banister).

The period of climbing of examinee with the AK prosthesis lasted longer than the period of healthy examinees: on shallow staircase 51,97 \% longer, on moderate staircase for 31,28 \% and on steep one $18,13 \%$ longer.

In order to achieve stability and prepare for climbing, the amputee stands near the first step, and positions his AK prosthesis so the foot is touching the stair with the front part and is inclined to the surface of the stair. When the subject feels stable, the handle of the manifold is pulled from the neutral position and the piston of the hydraulic cylinder starts to pull out. Because of the increase in pressure in the hydraulic installation and movement of the piston, the heel of the prosthetic foot strikes the stair and almost simultaniously the healthy leg is raised from the ground. Since the prosthetic foot is held completely onto the stair, the force of the cylinder extends the AK prosthesis in the knee joint and lifts the body of the transfemoral amputee. At the moment that the prosthetic heel lands on the step, the left leg separates from the ground and is swung up in order to get it onto the second step and lift the body.

The curve of the vertical reaction force of a person with the AK prosthesis looks like the one for nonamputee (Fig. 8).

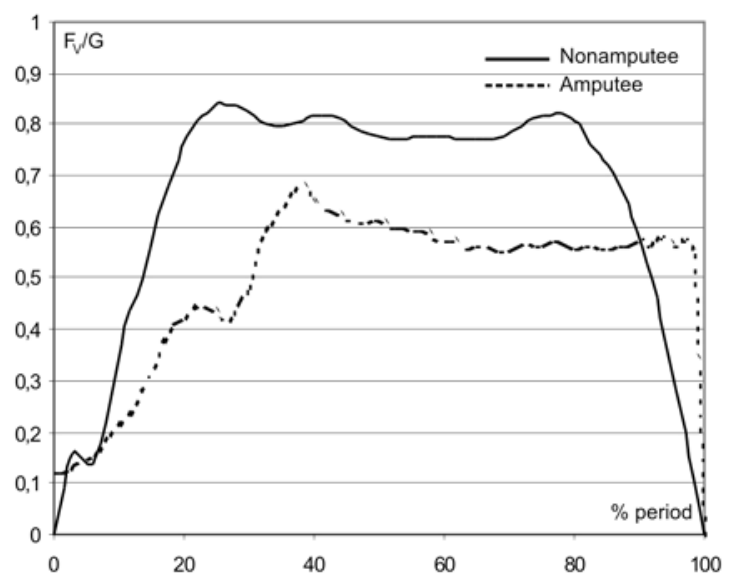

Figure 8: Diagrams of the vertical reaction forces for a person with driven AK prosthesis and nonamputee (moderate staircase). 
During the stair-climbing with using a banister hand-hold on the left side, the first peak on vertical reaction curve was lower than the same peak for nonamputee for $27 \%$ (SH), $16 \%$ (M) and $38 \%$ (ST); The second peak was lower for $26 \%(\mathrm{SH}), 24 \%(\mathrm{M})$ and $18 \%(\mathrm{ST})$; The valley was lower for $28 \%$ (SH), $22 \%(\mathrm{M})$ and $27 \%$ (ST).

During the climbing of the amputee, the vertical reaction force was much lower than vertical reaction force for nonamputee due to stronger releasing on banister in order to achieve safe climbing and also because of a force of the hydraulic cylinder which lifted a body of the amputee.

During the climbing of examinee with the AK prosthesis with the use of a banister handhold on the left side and horizontal pulling force by right hand, the vertical reaction force of the stair was little greather than the same force during the climbing with the use of a banister only. The averige pulling force was $0,29 \mathrm{G}(0,24-0,38)$, where $\mathrm{G}$ is weight of a transfemoral amputee. The first peak was greather for $3 \%(\mathrm{SH}), 6 \%(\mathrm{M})$ and $2 \%(\mathrm{ST})$. The second peak was greather for $3 \%(\mathrm{SH}), 2 \%(\mathrm{M})$, and $1 \%(\mathrm{ST})$. The valley of curve of the vertical reaction force was greather for $5 \%(\mathrm{SH}), 9 \%(\mathrm{M})$ and $5 \%(\mathrm{ST})$. This small increasing of the vertical reaction force during the climbing with horizontal pulling force was result of better stability and safety of the amputee, so his releasing was weaker.

\section{CONCLUSION}

By the kinematic analysis of movement of an AK prosthesis with a built-in hydraulic cylinder connected to an external source of power, it can be concluded that a hydraulic installation with $100 \times 10^{5} \mathrm{~Pa}$ as nominal pressure can be used for stair-climbing with the use of a banister hand-hold. Complete analysis of the climbing of a transfemoral amputee carrying an externally driven prosthesis has shown that it is feasible to create a drive for an AK prosthesis for stair-climbing with a unit whose weight and over-all dimensions would not interfere with the comfort of the prosthesis user.

This study established that the way of climbing upstairs makes important impact on vertical reaction force of the stair. The greathest impact on reaction force is made by climbing with use of a banister hand-hold. Analysing the vertical reaction force of the stair during the climbing of a person with the AK prosthesis with hydraulic cylinder built in the knee joint and connected with an external source of power, it is established that the vertical reaction force is smaller than the same force during the climbing for nonamputees. This is the result of stronger releasing of amputee on a banister in order to achieve safe climbing and also acting of the hydraulic cylinder force which lifts the body of the amputee. These results leed us to conclusion that it is feasible to create a drive for an AK prosthesis for stair-climbing with a unit whose weight and over-all dimensions would not interfere with the comfort of the prosthesis user.

\section{REFERENCES}

[1] Putti, V. (1930). Historic Artifical Limbs

[2] Ayyappa, E. (1999). Gait characteristics of the transfemoral amputee, BioMechanics, IX

[3] Begg, R. K.; Wytch, R.; Hutchison, J.; Wardlaw, D. (1991). Microcomputer-based system for clinical gait studies, Clinical Biomechanics, No. 6, 168-172

[4] Ross, J. (1999). The clinical and educational applications of the gait analysis of the gait analysis laboratory into the $21^{\text {st }}$ century, Prosthetics 
[5] Flowers, W. C.; Mann, R. W. (1977). An elektrohydraulic knee-torque controller for a prosthesis simulator, Journal of Biomechanical engineering, No. 2

[6] Zarrughi, M.Y. (1976). Simulation of swing phase dynamics in above-knee prostheses, Biomechanics, No. 9, 285-292

[7] Tsai, P. J.; Ju, M. S.; Tsuei, Y. G. (1993). Development of electrohydraulic controlled aboveknee prostheses, JSME International Journal, Vol. 36, No. 3

[8] Wang, T. K.; Ju, M. S.; Tsuei, Y. G. (1992). Adaptive control of above knee electro-hydraulic prosthesis, Journal of Biomechanical Engineering, Vol. 114, No. 8

[9] Rigas, C. (1985). Active plantar-flexion above-knee prosthesis: concept and preliminary design, Prosthetics and orthotics International, No. 9, 141-144

[10] Rigas, C. (1978). Voluntarily controlled telescopic above-knee prosthesis, $\mathrm{PhD}$ Thesis, University of Strathclyde, Bioengineering Unit

[11] Rigas, C.; Solomonidis, S. E.; Berme, N.; Kenedi, R. M. (1979). New unconventional prosthesis for above-knee amputees, Disability - London, 375-384

[12] Seliktar, R. (1971). Self energized power system for above-knee prosteheses, Journal of biomechanics, No. 4, 431-435

[13] Zahedi, S. (2000). The Inteligent Prosthesis Plus, Blatchford Products Division, UK

[14] Nader, M.; Nader, H. G. (2002). C-Leg. Excerpt from the Otto Bock Prosthetic Compendium

[15] Hudec, M. (2001). Enclosure to the analysis of hydraulic components for above-knee prosthesis, M.A. examination, Faculty of mechanical engineering, Mostar

[16] Dedic, R.; Vucina, A.; Hudec, M. (2001). Simulation of climbing up the various types of stairs with above knee prosthesis, International Conference UPS Mostar - Proceedings

[17] ELITE System Manual (1994). BTS, Milano 